\title{
Equine spermatozoa viability comparing the NucleoCounter SP-100 and the eosin- nigrosin stain
}

Johansson, C.S.; Matson, F.C.; Lehn-Jensen, Henrik; Nielsen, J.M.; Petersen, Morten Møller

\section{Published in:}

Animal Reproduction Science

DOI:

10.1016/j.anireprosci.2008.05.102

Publication date:

2008

Document version

Publisher's PDF, also known as Version of record

Citation for published version (APA):

Johansson, C. S., Matson, F. C., Lehn-Jensen, H., Nielsen, J. M., \& Petersen, M. M. (2008). Equine spermatozoa viability comparing the NucleoCounter SP-100 and the eosin-nigrosin stain. Animal Reproduction Science, (3-4), 24-25. https://doi.org/10.1016/j.anireprosci.2008.05.102 
may have positive effects on spermatozoa motility after $48 \mathrm{~h}$ cooling, and further investigation is warranted.

doi:10.1016/j.anireprosci.2008.05.101

23

Equine spermatozoa viability comparing the NucleoCounter SP-100 and the eosin nigrosin stain

C.S. Johansson ${ }^{\text {a }, \text { F.C. Matsson }}{ }^{\text {a }}$, H. Lehn-Jensen ${ }^{\text {a }}$, J.M. Nielsen ${ }^{\text {b }}$, M.M. Petersen ${ }^{\text {a,* }}$

${ }^{a}$ Veterinary Reproduction and Obstetrics, Department of Large Animal Sciences, Faculty of Life Sciences, Copenhagen University, Denmark

${ }^{\mathrm{b}}$ Ansager Equine Hospital, Ansager, Denmark

E-mail address: mmpe@life.ku.dk (M.M. Petersen).

The objective of this study was to assess spermatozoal viability using eosin-nigrosin stain (E-N) and the NucleoCounter SP-100 (NC) and correlate viability to progressive motility and morphology. Spermatozoal viability or integrity of the sperm plasma membrane can be evaluated in several ways. Under field conditions, spermatozoal viability can be assessed using either classical stains, like E-N, or using the NC. When using the E-N stain, eosin is occluded from spermatozoa with an intact membrane, but penetrates membrane damaged cells. E- $\mathrm{N}$ is a subjective test using light microscopy and 100-200 spermatozoa are counted. The NC is an integrated fluorescence microscope that counts the number of spermatozoa (approximately 1500) stained with propidium iodide (PI). PI has been used extensively to stain non-viable spermatozoa (Love et al., 2003). Looking at boar semen the accuracy and repeatability of the NC was identical to the flow cytometer (Hansen et al., 2006). Further information on the NC at www.chemometec.dk. Spermatozoa viability using $\mathrm{E}-\mathrm{N}$ and the $\mathrm{NC}$ as well as progressive motility and morphology were assessed in 72 ejaculates ( 8 ejaculates from 9 stallions) on a Danish stud farm at regular intervals throughout the breeding season 2007. Of the evaluated ejaculates, 3 were not included in the dataset due to suboptimal E-N slide preparation. Progressive motility was assessed immediately after collection in extended semen. Spermatozoal morphology was determined using the $\mathrm{E}-\mathrm{N}$ stain ( 200 cells). In 67 of the 69 evaluated ejaculates the percentage of viable cells was higher when determined by $\mathrm{E}-\mathrm{N}$ compared to the NC. The mean difference in spermatozoal viability determined by $\mathrm{E}-\mathrm{N}$ and NC was $12.5 \%$, but the difference was not significant $(p=0.09$, two sample test for proportions). Spearman's correlation coefficient $(r)$ was $0.64(p<0.001)$. Sperm viability determined by $\mathrm{E}-\mathrm{N}$ and NC correlated significantly to progressive motility and morphology: $r=0.72$ and 0.57 and $r=0.79$ and $0.60(p<0.001)$, respectively. The fact that viability in 67 of 69 ejaculates was higher when using $\mathrm{E}-\mathrm{N}$ compared to the $\mathrm{NC}$, could be explained by the fundamental difference in the two methods (eosin vs. PI). The subjectivity of E-N could very likely be a cause of variation since the difference between eosin stained or unstained spermatozoa is sometimes subtle. 


\section{Reference}

Hansen, C., Vermeiden, T., Vermeiden, J.P.W., Simmet, C., Day, B.C., Feitsma, H., 2006. Comparison of FACSCount AF system, Improved Neubauer hemocytometer, Corning 254 photometer, SpermVision, UltiMate and NucleoCounter SP-100 for determination of sperm concentration of boar semen. Theriogenology 66, 2188-2194.

Love, C.C., Thompson, J.A., Brinsko, S.P., Rigby, S.L., Blanchard, T.L., Lowry, V.K., Varner, D.D., 2003. Relationship between stallion sperm motility and viability as detected by two fluorescence staining techniques using flow cytometry. Theriogenology 60, 1127-1138.

doi:10.1016/j.anireprosci.2008.05.102

24

Prostaglandin $\mathrm{E}_{2}$ concentrations and sperm motility in fractionated stallion ejaculates

A.M. Kareskoski ${ }^{\text {a }}$, H. Kindahl ${ }^{\text {b }}$, M. Andersson ${ }^{\text {a }}$, T. Katila ${ }^{\text {a,* }}$

a Department of Production Animal Medicine, University of Helsinki, Pohjoinen Pikatie 800, 04920 Saarentaus, Finland

${ }^{\mathrm{b}}$ Faculty of Veterinary Medicine and Animal Science, SLU, Box 7054, 75007 Uppsala, Sweden

E-mail address: maria.kareskoski@ helsinki.fi (T. Katila).

Stallion ejaculates are formed by several fractions that differ in their composition and sperm concentration. Information on prostaglandin levels in stallion seminal plasma (SP) is scarce, but it has been shown that decreased levels of prostaglandin E (PGE) associated with NSAID therapy do not affect semen characteristics and freezability (Janett et al., 2005). The purpose of this study was to compare the concentrations of $\mathrm{PGE}_{2}$ in different fractions of $\mathrm{SP}$, and to evaluate the correlation of the concentration and total amount of $\mathrm{PGE}_{2}$ with semen volume, sperm concentration and motility. Semen from 41 stallions was collected as three separate fractions: the first sperm-rich fraction with possible pre-ejaculatory fluid (FR1), the latter portion of the sperm-rich fraction (FR2) and the sperm-poor fraction (FR3). The volume of each sample was recorded and the sperm concentration was determined with a Bürker counting chamber. A portion of each fraction was combined to a sample representing the whole ejaculate (WE). A part of each fraction was centrifuged at $4000 \times g \times 15 \mathrm{~min}$, then the supernatant was removed, filtered with $0.45 \mu \mathrm{m}$ filters and frozen $\left(-75^{\circ} \mathrm{C}\right)$ in $1.5-\mathrm{ml}$ vials. The remaining part of each fraction was centrifuged at $500 \times g \times 10 \mathrm{~min}$, resuspended in a mixture of SP and skim milk extender (ratio 1:2) and stored at $5^{\circ} \mathrm{C}$ for $24 \mathrm{~h}$. The PGE $\mathrm{PG}_{2}$ concentrations in SP were analyzed with commercial enzyme immunoassay kit (Assay Designs Inc., MI, USA). A computerized motility analyzer (SpermVision) was used to determine sperm motility parameters. There were significant differences between fractions in the concentration of $\mathrm{PGE}_{2}$. FR3 had significantly lower values $(257.0 \pm 92 \mathrm{ng} / \mathrm{ml})$ compared with the other fractions (FR1: $359.4 \pm 190 \mathrm{ng} / \mathrm{ml}, \mathrm{FR} 2: 387.7 \pm 167 \mathrm{ng} / \mathrm{ml}$ and WE: $353.5 \pm 134 \mathrm{ng} / \mathrm{ml}$ ). No significant correlations were found between the concentration or total amount of $\mathrm{PGE}_{2}$ and sperm concentration, total sperm count or semen volume, even though the sperm concentration was significantly lower in FR3 $\left(123 \times 10^{6} \mathrm{sperm} / \mathrm{ml}\right)$ compared with FR1 $\left(284 \times 10^{6} \mathrm{sperm} / \mathrm{ml}\right)$ and FR2 $\left(240 \times 10^{6} \mathrm{sperm} / \mathrm{ml}\right)$. The differences between fractions in total motility and progressive motility were non-significant, but the sperm average path velocity was higher in FR3 compared with FR1, FR2 and WE. There were no significant correlations between $\mathrm{PGE}_{2}$ levels and the motility parameters. The lowest $\mathrm{PGE}_{2}$ concentration was found in the last sperm-poor fraction of the ejaculate. $\mathrm{PGE}_{2}$ levels were not correlated to any of the measured 